\title{
SPEKTROSCOPI FTIR DAN SIFAT MEKANIK NANOKOMPOSIT GRAFTING HDPE DAN NANOPRECIPITATED CALCIUM CARBONATE (NPCC)
}

\section{(FTIR SPECTROSCOPY AND MECHANICAL PROPERTIES OF NANOCOMPOSITES GRAFTING HDPE AND NANOPRECIPITATED CALCIUM CARBONATE)}

\author{
Arum Yuniari dan Emiliana Kasmujiastuti \\ Balai Besar Kulit, Karet dan Plastik, Yogyakarta \\ Email: arumyuniari@yahoo.com \\ Diterima: 10 Juli 2012 \\ Direvisi: 16 Oktober 2012 \\ Disetujui: 15 Nopember 2012
}

\begin{abstract}
The purpose of this research based on high density polyethylene (HDPE) and nanoprecipitated calciumcarbonate (NPCC) was to evaluate the effect of nanoprecipitated calcium carbonate (NPCC) on FTIR spectroscopy and mechanical properties. The nanocomposites was prepared with a rheomix 3000 Haake at $180^{\circ} \mathrm{C}$ and $50 \mathrm{rpm}$ of rotor speed for 10 minutes. The composition of HDPE and additives were permanently, and NPCC content varied 10, 15, 20, 30, 40 and $50 \mathrm{phr}$ (per hundred resin) respectively and control was made inherent NPCC. The nanocomposites were characterized using tensile strength, hardness tester, electro densimeter and Fourier Transform Infra Red (FTIR) spectroscopy techniques. The results of mechanical properties showed that the increasing the amount of NPCC was able increase hardness and density while elongation at break more stable and tensile strength decreased. Analysis functional group on nanocomposites with Fourier Transform Infra Red (FTIR) indicated a new peak on wave band $3472,49 \mathrm{~cm}^{-1}$ (OH stretching).
\end{abstract}

Key words: HDPE, NPCC, FTIR, mechanical properties

\begin{abstract}
ABSTRAK
Penelitian tentang pembuatan nanokomposit dari bahan high density polyethylene (HDPE) dan nanoprecipitated calciumcarbonate (NPCC) bertujuan untuk mengetahui pengaruh penambahan filler NPCC terhadap sifat mekanik dan spektroscopi. Nanokomposit dibuat dengan Rheomix 3000 Haake pada suhu $180^{\circ} \mathrm{C}$ dan kecepatan $50 \mathrm{rpm}$ selama 10 menit. Komposisi HDPE dan bahan aditif dibuat tetap, dan kandungan NPCC divariasi berturut-turut $10 ; 20 ; 30$; 40 dan 50 phr (per hundred resin) dan dibuat kontrol tanpa ditambah NPCC. Sifat mekanik diuji dengan alat uji tensile strength, hardness, densimeter dan karakterisasi gugus fungsi ditentukan menggunakan Fourier Transform Infra Red (FTIR). Hasil uji sifat mekanik menunjukkan semakin tinggi jumlah NPCC kekerasan dan densitas naik, kemuluran tetap sedangkan kuat tarik cenderung turun. Spektrum nanokomposit HDPE/NPCC menunjukkan terjadinya puncak baru pada bilangan gelombang $3472,49 \mathrm{~cm}^{-1}$ (OH stretching).
\end{abstract}

Kata kunci: HDPE, NPCC, FTIR, sifat mekanik

\section{PENDAHULUAN}

Nanokomposit dengan kandungan calcium carbonat $\left(\mathrm{CaCO}_{3}\right)$ rendah merupakan polimer yang sangat diminati, hal ini disebabkan nanokomposit mempunyai sifat mekanik tinggi dan ketahanan termal serta sifat barrier yang dimiliki relatif baik (Pinnaviaia, et al., 2000 cit Mahmood, et al., 2009). Dalam kelompok poliolefin, polyethylene (PE) sering digunakan dalam pembuatan nanokomposit karena memiliki rantai molekul nonpolar. Polyethylene merupakan salah satu polimer 
dengan struktur molekul paling sederhana, bersifat termoplastik dibuat dari polimerisasi ethylene $\left(\mathrm{C}_{2} \mathrm{H}_{4}\right)$. Polimer termoplastik adalah polimer yang dapat mencair dan mengalir pada suhu tinggi. High Density Polyethylene (HDPE) dihasilkan dari proses polimerisasi monomer ethylene pada suhu dan tekanan rendah dengan berbagai katalisator umumnya adalah logam transisi seperti krom dan titanium, kadang-kadang digunakan cocatalyst seperti aluminium alkyl.

Precipitated Calcium Carbonate (PCC) adalah produk turunan kapur yang telah mengalami proses rekarbonisasi. PCC umumnya dibuat dari batuan kalsium karbonat dengan kemurnian tinggi. PCC dikenal sebagai kalsium karbonat yang dimurnikan. Bentuk umum dari PCC adalah kristal heksagonal yang dikenal dengan calsite, dengan turunannya adalah skalenohedral, rhombohedral dan prismatik. Bentuk lainnya adalah aragonite dan vaterite $\mathrm{PCC}$ dibuat dari sintesa slurry $\mathrm{CaCO}_{3}$ dan gas $\mathrm{CO}_{2}$ dengan suhu $0-60^{\circ} \mathrm{C}$. PCC yang dihasilkan partikel terkecil dengan ukuran 1,5-6,5 $\mu \mathrm{m}$ dan partikel terbesar berukuran 15-25 $\mu \mathrm{m}$ (Gane, et al., 2010 ; Jasminka, K. et al., 2011).

Nano- partikel adalah partikel yang mempunyai ukuran $<100 \mathrm{~nm}$ atau $0,1 \mu$. Nano partikel telah dikenal dalam beberapa tahun terakhir sedangkan jenis nano-PCC telah digunakan secara komersial lebih lama lagi. Nano-PCC jenis SMI's ultrafine diproduksi dalam berbagai ukuran partikel dari $0,06 \mu \mathrm{m}$ atau $60 \mathrm{~nm}$ sampai dengan dengan $0,15 \mu \mathrm{m}$ atau $150 \mathrm{~nm}$. Keunggulan nano ultrafine PCC yaitu dalam aplikasi polimer akan meningkatkan dispersi filler dan meminimalkan interaksi dengan aditif polimer lainnya.

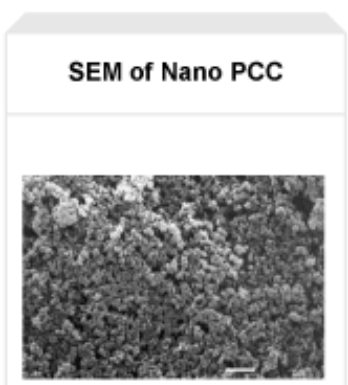

Gambar 1. Mikrograf SEM dari nano PCC
Menurut Bhattacharya, et al. (2009) teknik utama untuk membuat polimer multikomponen adalah dengan metode physiosorption, grafting dan ikatan silang, yaitu menggabung berbagai komponen fungsional dalam bahan tunggal. Pemisahan mikro dan makrophase langsung mempengaruhi sifat fisika dan kimia dari polimer multi komponen. Graft kopolimer adalah gabungan beberapa makromolekul yang bercabang dan memiliki tipe ikatan yang berbeda. Grafting adalah proses ikatan kovalen dan irreversible. Skema diagram Physiosorption, grafting dan crosslinking terdapat pada Gambar 2. Physiosorption, grafting dan crosslinking merupakan teknik untuk menggabungkan polimer dan monomer. Physiosorption berkaitan dengan sifat fisika, prosesnya reversibel satu dengan yang lain berhubungan pada permukaannya atau dihubungkan dengan surfactant.

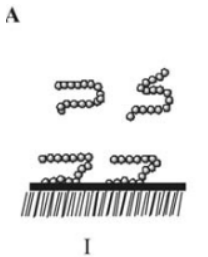

B

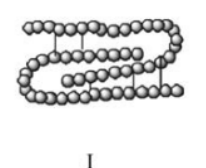

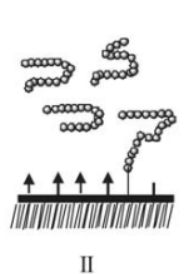

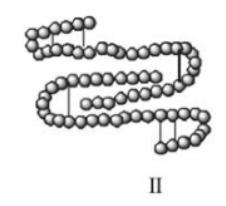

Gambar 2. Skema diagram (I) physiosorption, (II) grafting to, (III) grafting dari B. skema diagram (I) crosslinking intermolekular dan (II) crosslinking intramolekular
Mahmood, et al (2009) dalam penelitiannya tentang HDPE-g-MA/clay nanokomposit melaporkan bahwa terjadi interkalasi cukup tinggi antara partikel clay sehingga kuat tarik nanokomposit relatif tinggi, disamping itu maleat anhidrat dapat menaikkan tingkat interkalasi. Polimerisasi antara HDPE dan $\mathrm{CaCO}_{3}$ menyebabkan terjadinya ekfoliasi $\mathrm{CaCO}_{3}$ kedalam matriks HDPE (Alexandre, et al., 2002). 


\section{BAHAN DAN METODE PENELITIAN}

\section{Bahan penelitian}

Bahan baku yang digunakan pada penelitian ini adalah plastik jenis high density polyethylene (HDPE) produksi dalam negeri merek Asrene SI 5230 injection grade dengan melt temperature $175-235^{\circ} \mathrm{C}$. Filler nano precipitated calcium carbonate (NPCC) yang digunakan merek SHENGKE dengan spesifikasi NPCCA-601, $\mathrm{CaCO}_{3}$ (coated) $\geq$ $95 \%$, bentuk partikel: kubus, ukuran partikel rata-rata: $40 \mathrm{~nm}$, kadar air $0.5 \%$, brightness $\geq$ 90\%, absorpsi minyak: 25-40 $\mathrm{ml} / 100 \mathrm{~g}$, specific gravity: $2,5 \mathrm{~g} / \mathrm{cm}^{3}$, specific surface area $(\mathrm{BET}) \geq 20 \mathrm{~m}^{2} / \mathrm{g}, \mathrm{HCl}$ insoluble: $0,1-$ $0,2 \%$, derajat aktivitas: $\geq 99 \%, \mathrm{pH}: 8,5-10,5$. Maleat anhidrat (MA) sebagai compatibilizer, dicumyl peroksida (DCP) sebagai inisiator, antioksidan (AOX), antimoni trioksida sebagai flame retardant dari Jerman, calsium stearat sebagai heat stabilizer buatan Singapura merk FACI, dan asam stearat sebagai lubricant produksi lokal.

\section{Alat penelitian}

Peralatan untuk pembuatan nanokomposit terdiri atas:timbangan digital merk Mettler Toledo, Hot Blender : Rheomic 3000 Haake, hydraulic press MN Vulcanizing Press Spec XLB, D 400 x 400 x1, tahun 2000, mesin pelletizing merk Suzhou, dan injection molding Merk COSMO, kode TTI 330/100HT.

Alat uji meliputi: untuk uji morfologi: Fourier Transform Infra Red (FTIR) merk Shimadzu IR Prestige 21, AIM-8800, alat uji sifat mekanik: tensile strength tester merk Troning Albert tipe QC II-M-18, hardness tester merk Toyoseiki (Durometer D), dan Electro Densimeter merk Mirage EW-200SG.

\section{Metode penelitian}

Nanokomposit dibuat dari campuran HDPE, NPCC serta bahan aditif. Perbandingan HDPE/NPCC dalam formulasi yang diteliti adalah $100 / 10 ; 100 / 20 ; 100 / 30$, 100/40; 100/50 dan sebagai kontrol digunakan perbandingan HDPE/PCC 100/0. Bahan lainnya adalah flame retardant, asam stearat, anti oksidan, compatibilizer dan inisiator dibuat tetap. Bahan -bahan ditimbang sesuai formulasi dan dicampur dalam mesin Rheomix 3000 Haake pada suhu $180^{\circ} \mathrm{C}$ selama 10 menit dengan kecepatan rotor $50 \mathrm{rpm}$. Campuran dialirkan ke mesin pelletizing sehingga diperoleh butiran nanokomposit. Nanokomposit dipress dengan mesin hydraulic press bertekanan $150 \mathrm{~kg} / \mathrm{cm}^{2}$ untuk persiapan pengujian.

\section{Pengujian sifat nanokomposit}

Pengujian dilakukan untuk mengetahui kualitas nanokomposit HDPE/NPCC, yang meliputi uji sifat mekanik: densitas, kuat tarik, kemuluran, dan kekerasan. Uji densitas dilakukan menggunakan alat densimeter dan mengacu metode uji ASTM D792. Uji kuat tarik dan kemuluran dilakukan dengan menggunakan alat uji tensile strength tester, uji kekerasan menggunakan hardness tester. Karakterisasi gugus fungsi nanokomposit menggunakan alat Fourier Transform Infra Red (FTIR).

\section{HASIL DAN PEMBAHASAN}

\section{Analisa Infrared Spectroscopy}

Karakterisasi gugus fungsi nanokomposit HDPE/NPCC ditentukan dengan alat Fourier Transform Infra Red Spectrophotometer (FTIR) dan hasil pantauan gugus fungsi disajikan pada Gambar $3,4,5$ dan 6 .

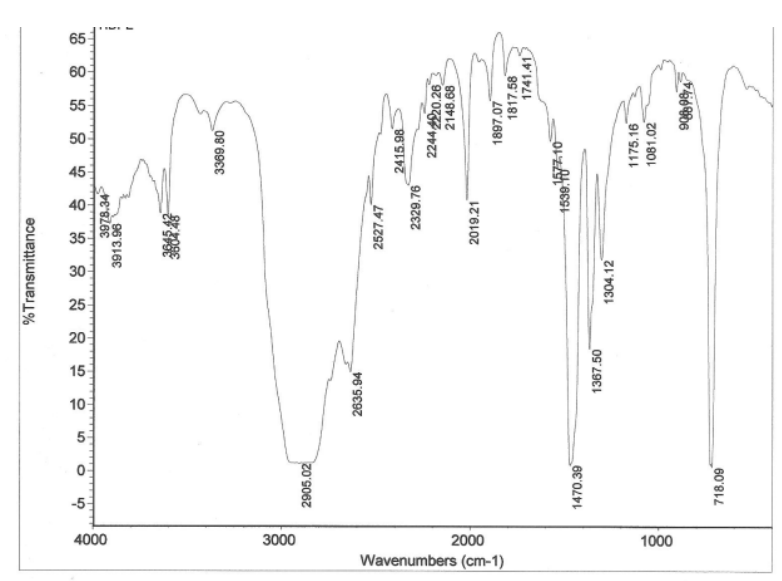

Gambar 3. Spektrum FTIR HDPE 


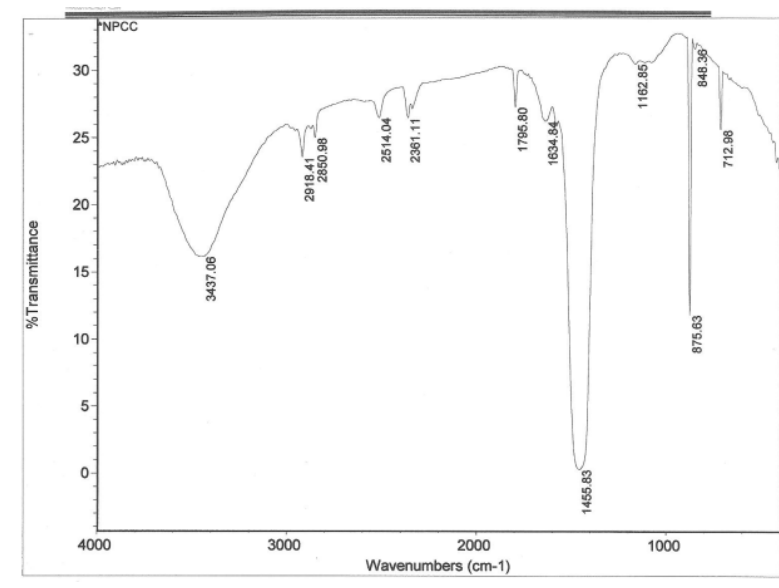

Gambar 4. Spektrum FTIR NPCC

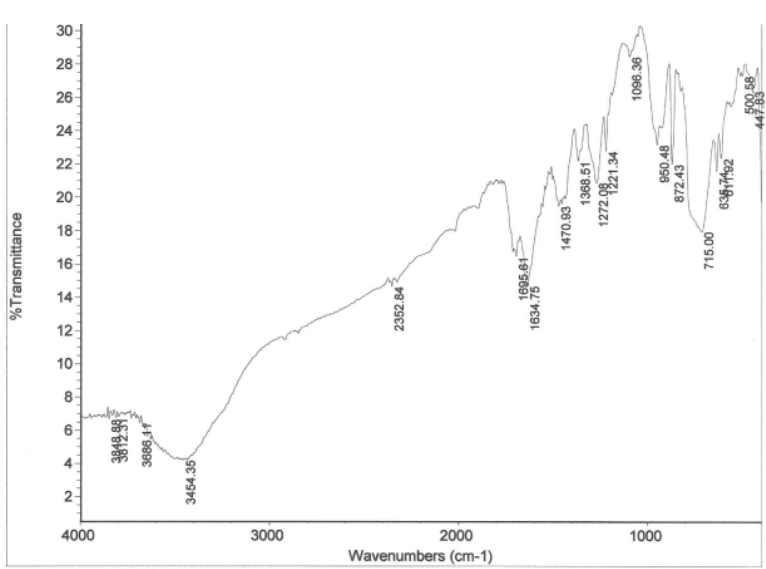

Gambar 5. Spektrum FTIR komposit tanpa NPCC

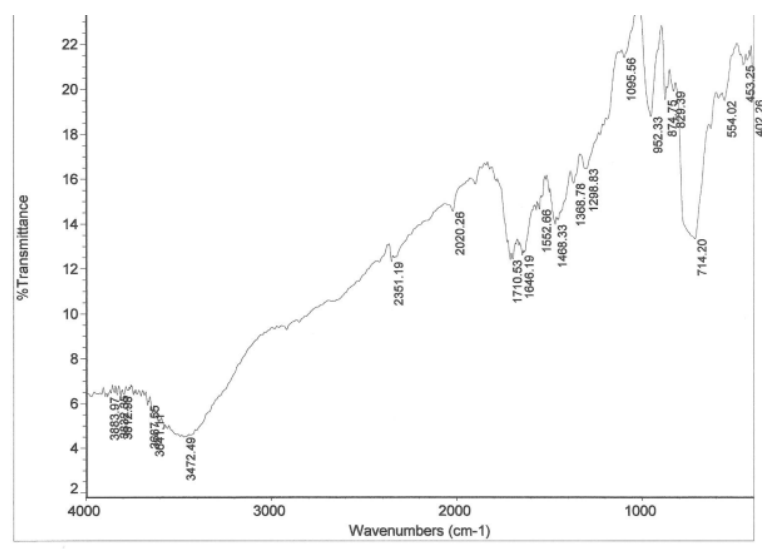

Gambar 6. Spektrum FTIR nanokomposit dengan NPCC 5 phr

Gambar 3. spektrum FTIR HDPE menggambarkan pita serapan didaerah didaerah bilangan gelombang berturut-turut: 3913,96-3604,48; 2905,02 $\mathrm{cm}^{-1}$ (C-CH3),
$2635,94 \mathrm{~cm}^{-1}, 1470,39-1539,10 \mathrm{~cm}^{-1}(\mathrm{C}=\mathrm{C})$, $1304,12-1367,50 \mathrm{~cm}^{-1}(\mathrm{C}-\mathrm{H}), 11751,16 \mathrm{~cm}^{-1}$, $1081,02 \mathrm{~cm}^{-1}\left(\mathrm{CH}_{2}\right), 718,09 \mathrm{~cm}^{-1}$ (acetate) (Peacock, 2000). Spectra nano precipitated calcium carbonate (Gambar 4) terdiri atas beberapa puncak kuat didaerah 3437,06; 2918,41 - 1795,$8 ; 1800 ; 1634,84 ; 1455,83$ (vaterite), 1162,$85 ; 875,63 \mathrm{~cm}^{-1}$ (calcite) dan $712,98 \mathrm{~cm}^{-1}$ (aragonite) (Kevin, 2004; Saeedi, $\mathrm{M}$ and Salman, J, S., 2011). Spektrum FTIR komposit HDPE tanpa NPCC (Gambar5) terlihat adanya puncak serapan didaerah bilangan gelombang berturut-turut: 1710,53 $\mathrm{cm}^{-1}$ asymetric streching dari carbonyl $(\mathrm{C}=\mathrm{O})$ dari maleat anhidrat dan $1695,61 \mathrm{~cm}^{-1}$ symetric streching dari carbonyl $(\mathrm{C}=\mathrm{O})$ dari maleat anhidrat sedangkan puncak serapan didaerah $715 \mathrm{~cm}^{-1}$ (C-H stretching). Spektrum FTIR nanokomposit HDPE/NPCC (Gambar 6) menunjukkan puncak serapan didaerah 3883,97-3472,49 $\mathrm{cm}^{-1}$ (OH stretching); 2351,19-2020,28; 1710,53 $\mathrm{cm}^{-1}$ (OH); 1646,$19 ; 1468,33 ; 874,75$, dan 714,20 $\mathrm{cm}^{-1}$ (CH stretching) (Durmus, et al., 2007).

\section{Sifat mekanik nanokomposit}

\section{Kekerasan nanokomposit}

Kekerasan nanokomposit disajikan pada Gambar 7. kekerasan komposit makin naik sejalan dengan bertambahnya jumlah bahan pengisi NPCC. Hal ini dikarenakan NPCC merupakan filler kaku dan kristalin maka makin banyak NPCC yang ditambahkan akan mengisi matriks HDPE dengan demikian kekerasan komposit akan naik.

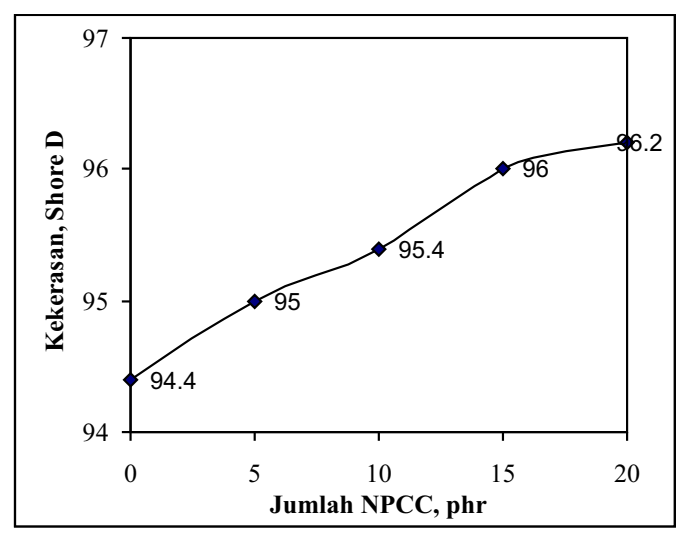

Gambar 7. Grafik kekerasan nanokomposit HDPE/NPCC 
Gambar 7. memperlihatkan bahwa penambahan NPCC 5 phr hanya menaikkan kekerasan $0,64 \%$, dan penambahan NPCC sampai 20 phr menaikkan kekerasan sampai $1,9 \%$. Walaupun penambahan NPCC tidak begitu banyak namun tetap ada interaksi interfacial adhesion diantara NPCC dengan HDPE. Ukuran filler (NPCC) makin kecil ternyata memberikan interaksi interfacial yang makin besar. Hal ini juga senada dengan yang dilaporkan oleh Liang (2002) yang menyatakan bahwa penggunaan partikulat inorganic rigid dengan ukuran yang lebih kecil seperti $\mathrm{CaCO} 3$ dalam polimer dapat memperbaiki interfacial adhesion diantara matrik dan filler. Filler jenis NPCC hanya sedikit memiliki cacat permukaan dan mudah didispersikan kedalam matrik polimer.

\section{Kuat Tarik}

Pengaruh penambahan filler NPCC terhadap kuat tarik nanokomposit disajikan pada Gambar 8. Hasil uji menunjukkan makin banyak filler NPCC yang ditambahkan kuat tarik nanokomposit akan turun.

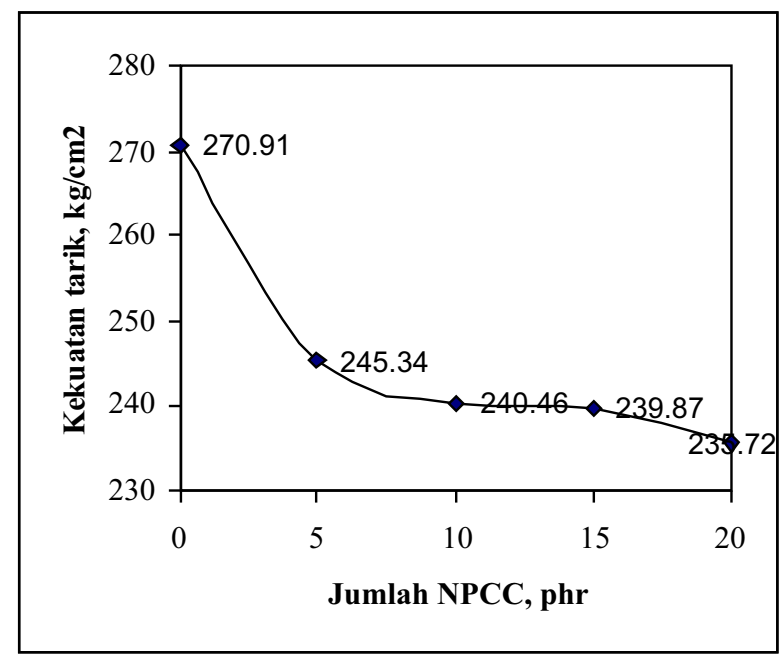

Gambar 8. Kuat tarik nanokomposit dengan filler NPCC

Hal ini dikarenakan interfacial adhesion diantara HDPE sebagai matrik dan filler NPCC melemah, sehingga bila ada tarikan tidak dapat menahannya yang menyebabkan komposit putus. Kuat tarik nanokomposit dipengaruhi oleh bentuk kristal dari filler, jenis kompatibiliser dan physicochemical. Kristal NPCC merupakan jenis kristal sangat kaku (150 - 250 GPA) yang dapat berakibat melemahkan interfacial adhesion (Durmus, et al., 2007 dan Durmus, et al., 2008 ). Pada Gambar 8 terlihat bahwa penambahan NPCC 5 phr nilai kuat tarik turun sebesar 9,44\%, dan penambahan sampai 20 phr kuat tarik turun sampai $13,03 \%$. Penambahan NPCC sampai 5 phr menghasilkan kuat tarik paling maksimal (Durmus, et al., 2007 dan Kusmono, 2010). Diameter partikel filler makin kecil maka makin banyak masa filler yang mengisi matrik antar molekul plastik sehingga mobilitas struktur HDPE berkurang. Hal ini berbeda dengan pendapat Mahmood, et al.(2009) yang mengatakan bahwa terjadi interkalasi cukup tinggi antara partikel NPCC sehingga kuat tarik nanokomposit tinggi, hal ini disebabkan dalam penelitian tersebut digunakan larutan dodecylamine sebagai bahan yang berfungsi untuk pendispersi dan adhesi NPCC dalam matrik polimer.

\section{Kemuluran}

Kemuluran nanokomposit disajikan pada Gambar 9. Kemuluran nanokomposit untuk semua variasi jumlah penambahan NPCC adalah sama yaitu $20 \%$.

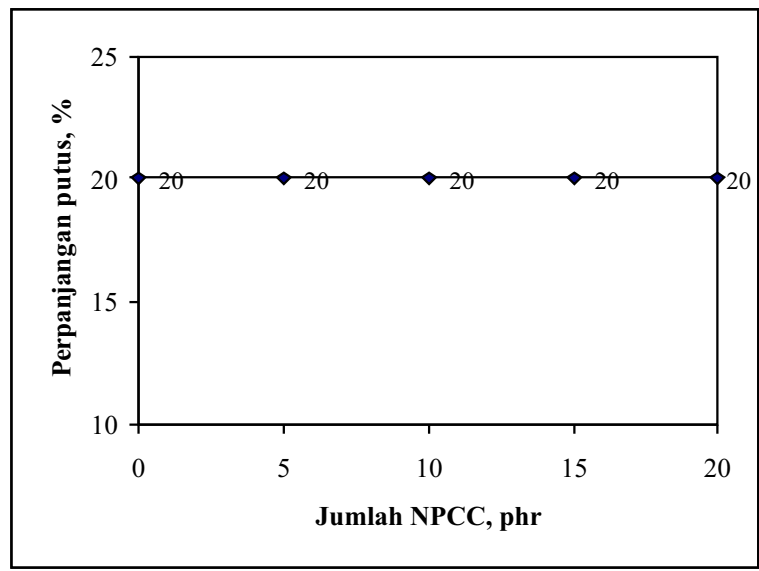

Gambar 9. Kemuluran nanokomposit dengan filler NPCC

Kemuluran nanokomposit dipengaruhi oleh jumlah NPCC dalam matriks campuran dan makin banyak jumlah NPCC yang ditambahkan maka kemulurannya makin turun, hal ini disebabkan terjadi interaksi yang 
kurang baik antara matriks polimer dan nano filler. Polimer akan kehilangan sifat-sifat plastiknya menyebabkan nanokomposit menjadi kaku (Supri,A.G.H. et al., 2008).

\section{Densitas}

Densitas nanokomposit disajikan pada Gambar 10. Densitas nanokomposit meningkat dengan bertambahnya jumlah filler NPCC. Kenaikan densitas nanokomposit dikarenakan densitas filler lebih tinggi dari densitas HDPE. Penambahan NPCC $5 \mathrm{phr}$ menaikkan densitas nanokomposit sebesar 2,75\%, dan penambahan NPCC $20 \mathrm{phr}$ menaikkan densitas nanokomposit sebesar 9,17\%. Menurut Gupta R.K. (1994) densitas HDPE $>0,954 \mathrm{gr} / \mathrm{cm}^{3}$.

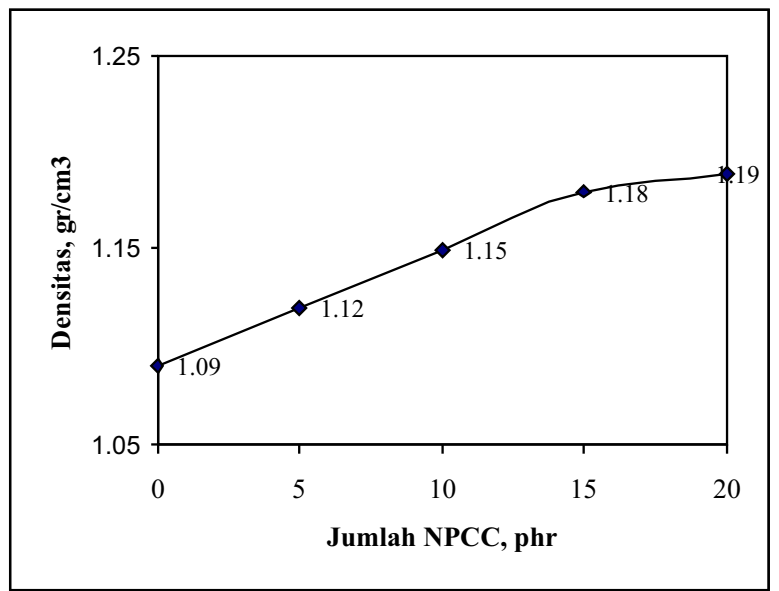

Gambar 10. Densitas komposit LHE dengan filler NPCC

\section{KESIMPULAN}

Sifat mekanik nanokomposit HDPE/NPCC menunjukkan bahwa kekerasan dan densitas naik seiring naiknya jumlah NPCC, nilai kekerasan tertinggi adalah 96,2 shore A dan nilai densitas tertinggi sebesar $1,19 \mathrm{gr} / \mathrm{cm}^{3}$. Sedangkan kuat tarik nanokomposit turun dengan meningkatnya jumlah NPCC. Kuat tarik terendah sebesar $235,72 \mathrm{~kg} / \mathrm{cm}^{2}$. Analisa gugus fungsi nanokomposit menunjukkan adanya puncak baru pada bilangan gelombang $3472,49 \mathrm{~cm}^{-1}$ (OH stretching).

\section{UCAPAN TERIMAKASIH}

Ucapan Terima kasih disampaikan kepada:

1. Ir.Dwi Wahini M.Eng yang telah membimbing dalam melakukan penelitian.

2. Dodi Irwanto, M.Eng yang telah mambantu dalam pelaksanaan penelitian.

\section{DAFTAR PUSTAKA}

Alexandre, M., Dubis, P., Sun, T., Garces, I.M. and Jerome, R., 2002. Polyethylene layered silicate nanocomposites prepared by the polymerization filling technique: synthesis and mechanical properties. Polymer, 43: 2123-2132.

Bhattacharya, A., James, W. R. and Paramitha, R., 2009. Polimer Grafting and crosslinking. A JohnWiley \& Sons, Inc. Publication ISBN 978-0-470-40465-2.

Durmus, A., Woo, M., Kasgos, A., Christopher, W.M and Tsapatsis, M., 2007. Intercalataed Linier Low Density Polyethylene (LLDPE/clay) Nanocomposites Prepared With Oxidized Polyethylene as a New type Compatibilizer, Structural, Mechanical and Barrier Properties. European Polymer Journal 43 : 3737-3749.

Durmus, A., Kasgos, A. and Christopher, W.M., 2008. Mechanical Properties of Linier Low Density Polyehylene (LLDPE)/clay Nanocomposites Estimation of aspect Ratio and interfacial Strength by Composites Models. Journal of Macromolecular Science.Part B Physics 47: 608-619. ISSN 022-2348.

Gane, Patrick, Arthur, Charles, Burl, Mathias, Pohl and Michael, 2010. Process to prepare Precipitated Calcium Carbonate Implementing Low Charge Acrylate A/O Maleinate- Containing Polymer. English. Patent No. Wo2010018432.

Gupta, R.K.,1994. Handbook of Small Scale Plastics Projects \& Processing Techniques. Small Business Publication, Roop Nagar, Delhi-India. 
Jasminka, K., Marko, U., Vesna, B.I. and Damir, K., 2011. Synthesis of Calcium Carbonate by Semicontinuous Carbonation Method in the Presence of Dextrans. Croatica Chemica ACTA CCACAA, ISSN 0011-1643, e ISSN 1334-417X Croat. Chem. Acta 84 (1) 25-32. CCA-3446.

Kevin, D.O.J., 2004. A Guide to Identifying Comnuce Inorganic Filler and Activators using Vibrational Spectroscopy The Internet Journal of Vibration Spectroscopy Vol 2/edition 3.

Kusmono, 2010. Studi Sifat Mekanik dan Morfologi Nanokomposit berbasis Poliamid 6/Polipropilen/Clay. Seminar Nasional Tahunan Teknik Mesin (SNTTM) ke 9 Palembang.

Liang, J.Z., 2002. Toughening and Reinforcing in Rigid Inorganic Particulate Filled Poly(propylene). Journal of Apllied Polymer Science Vol 83, Issue 7: 1547-1555.

Mahmood, M., Musa R.K., and Gustavo, Q., 2009. Maleic Anhydride Grafting onto HDPE, by In situ Reactive Extrusion and its Effect on Intercalation and Mechanical Properties of HDPE/Clay Nanocomposite. Iranian Polymer Journal 18: 10.
Pinnavaia, J. J. and Beall G.W., 2000. Polymer Nanocompsites. John Wiley, New York.

Peacock, A.J., 2000. Hand Book Of Polyethylene, Structures, Properties and Aplications marcel Dekker. Inc.

Saeedi, M. And Salman, J.S., 2011. Morphological and Thermal Properties of $\mathrm{HDPE} / \mathrm{CaCO}_{3}$ Nanocomposites, Effect of Content of Nano and MFI. International Conference on Nanotechnology and Biosensors. IPCBEE vol 25. IPCBEE vol 25 IACSIT Press. Singapore.

Supri, A.G.H., Salmah and Hazwan, K., 2008. Low Density Polyethylene-Nanoclay Composites, the Effect of Poly(acrylic acid) on Mechanical Properties, XRD, Morphology Properties and Water Absorption. Malaysian Polymer Journal (MPJ). Vol.3 No.2, p 39-53. 